e-Phaïstos

e-Phaïstos

Revue d'histoire des techniques / Journal of the history

of technology

VIII-1 | 2020

Écomusée : une expansion internationale

\title{
Écomusée, un concept voyageur
}

Eco-museum, a Traveling Concept

\section{Morgane Moëllo}

\section{OpenEdition}

Journals

Édition électronique

URL : http://journals.openedition.org/ephaistos/7556

DOI : 10.4000/ephaistos.7556

ISSN : 2552-0741

Éditeur

IHMC - Institut d'histoire moderne et contemporaine (UMR 8066)

\section{Référence électronique}

Morgane Moëllo, «Écomusée, un concept voyageur », e-Phaïstos [En ligne], VIII-1 | 2020, mis en ligne le 29 avril 2020, consulté le 06 mars 2021. URL : http://journals.openedition.org/ephaistos/7556 ; DOI : https://doi.org/10.4000/ephaistos.7556

Ce document a été généré automatiquement le 6 mars 2021.

Tous droits réservés 


\title{
Écomusée, un concept voyageur
}

\author{
Eco-museum, a Traveling Concept
}

\section{Morgane Moëllo}

1 Éco-logie, Éco-nomie, Éco-système ? Le trouble enveloppant le mot écomusée met en évidence la pluralité de son acception aux yeux des néophytes comme des praticiens du champ culturel et patrimonial. Son contexte d'invention, concomitant à la création des Parcs naturels régionaux et au Ministère de l'Environnement, lui confère une portée écologique, rurale et ethnographique, inspirée par les premières expériences de Marquèze et Ouessant. Au tournant des années 1970, ce concept polysémique se voulait plus largement échapper à l'inertie des musées traditionnels tournés vers les collections. Pour Georges-Henri Rivière, initiateur de cette nouvelle approche muséologique, il s'agissait d'inventer « un musée pas comme les autres», une « institution polyphonique, carrefour de l'espace et du temps » créée aux côtés d'une communauté, en interaction avec son environnement. La Fédération des écomusées et des musées de société a depuis proposé une définition recentrée sur son rôle de développement en accord avec la conception de l'inventeur du mot, Hugues de Varine. Pour autant, la définition évolutive de Georges-Henri Rivière stabilisée en 1980 reste un cadre sémantique de référence agissant comme un remède apaisant face à l'insaisissable processus, un moyen de rappeler son caractère performatif. Depuis, l'usage et l'usure du mot méritait que l'on y consacre un numéro de la revue d'histoire des techniques $e^{-}$ Phaïstos issu d'une journée d'études, à l'aune de 50 ans de pratiques et d'appropriations de ce concept voyageur.

2 Il y a dans l'éco-musée, ce projet social, éminemment politique, de remise en cause d'un paradigme patrimonial dont Claudia Da Re montre qu'il émane d'une approche holistique et inclusive du patrimoine culturel et naturel, matériel et immatériel. Un principe qui interroge la démarche écomuséale comme un possible terrain de préfiguration du Patrimoine Culturel Immatériel. En résulte un changement d'échelle, au bâtiment se substitue le territoire d'une communauté, espace privilégié d'études interdisciplinaires. C'est en analysant la place de la recherche dans la pratique du concept que Thierry Bonnot interroge la nature de son esprit d'innovation, prenant appui sur l'expérience de l'Écomusée Creusot Montceau. Dans l'exaltation des 
premières années, ce laboratoire de conception et d'expérimentation du prototype écomuséal cristallise l'attention des praticiens lors de nombreux voyages d'études. Pardelà cette aura nationale et internationale, son histoire mouvementée révèle la complexité de pérenniser l'innovation, compte tenu d'une vulnérabilité structurelle, expliquent Pauline Corrias, Typhaine Le Foll et Morgane Moëllo. Subsiste la singularité durable des écomusées : tendre vers la pyramide inversée d'un mode de gouvernance ascendant. Dans cette optique, la population est partie prenante si ce n'est initiatrice du projet, lui-même vecteur de développement social, économique et/ou environnemental.

3 Dès les années 1980, l'utopie muséale devient palimpseste lorsqu'elle échappe à ses inventeurs par les multiples réappropriations dont elle fait l'objet à travers le monde. Sa portée internationale figurait d'ores-et-déjà dans les prémices d'initiatives muséales communautaires des années 1960, au Mexique, au Niger et aux États-Unis. Sa force ne consiste-t-elle pas d'ailleurs dans la capacité d'adaptation du concept aux besoins de communautés plurielles sur des aires géographiques, culturelles et socio-économiques distinctes? Humberto Morales Moreno montre qu'au Mexique, creuset du «musée communautaire ", un centre d'interprétation sur la mémoire ouvrière et le paysage industriel devient un enjeu de gestion collective des territoires et de ses ressources, résolument tourné vers l'avenir. Dans les musées tchèques présentés par Marcela Efmertová et les écomusées d'Europe de l'est présentés par Mihaela Nichifor, la responsabilité de la communauté est engagée vis-à-vis de son territoire et de son patrimoine naturel et culturel pour le transmettre aux jeunes générations. L'écomusée y est vecteur de développement durable par le processus d'interprétation du patrimoine local, forme hybride d'entreprenariat culturel en milieu rural.

4 En ce début de XXI ${ }^{e}$ siècle, Bénédicte-Rolland Villemot analyse les analogies troublantes qui se font jour entre les débats à l'origine de la création des écomusées et ceux-là même qui animent le renouveau des musées. L'élan de modernité participative et sociale des débuts n'est plus l'apanage des écomusées. Absents des débats, les principes de l'écomusée ont pourtant fait florès dans le monde. On le constate notamment sur le continent africain pour lequel les expériences et projets présentés dans ce numéro tendent à échapper à la logique des musées traditionnels, suscités par les puissances coloniales ou par les gouvernements souverains, au moment des indépendances. Les projets ou réflexions en cours s'articulent notamment sur l'association entre les patrimoines naturels et culturels, comme en attestent les potentialités mises en avant par Noaga Birba, en vue de constituer un écomusée, à partir des bosquets sacrés de Koudougou, au Burkina Faso. Au Sénégal, une logique différente prévaut. Les pratiques et réflexions muséographiques sont déjà anciennes, mais ne prennent pas pleinement en compte la mosaïque ethnique, culturelle, religieuse et économique, du pays. Pour Boubacar Obeye Thioye, il serait donc souhaitable de davantage profiter de cette diversité culturelle, pour la promouvoir par le prisme de la mise en exergue d'un caractère spécifique : l'importance du patrimoine immatériel et de l'oralité ainsi que la nécessité de s'affranchir de la collection d'objets. Dans ces conditions, le modèle écomuséal semble particulièrement adapté aux enjeux de la préservation de l'imaginaire collectif propre à chacune des ethnies.

5 Ce faisant, l'importance croissante que les musées consacrent aux systèmes de valeurs et de représentations du monde extra-occidental résonne avec la force du concept voyageur. En définitive, les musées ne seraient-il pas tentés de devenir des écomusées? 
En tant que lieu de questions évoluant en miroir d'un environnement vivant, l'écomusée constitue son propre appareil critique. La parole est donc aux praticiens du concept !

\title{
INDEX
}

Mots-clés : écomusée, musée, muséologie

Keywords : eco-museum, museum, museology

\begin{abstract}
AUTEUR
MORGANE MOËLLO

Historienne des techniques de formation, Morgane Moëllo est spécialisée dans la conservation et la valorisation du patrimoine technique et industriel. En tant que conservatrice du patrimoine, elle a repris la direction de l'Écomusée Creusot Montceau au cours de l'année 2019. Son champ d'expertise porte sur l'impact technique et environnemental des aménagements industriels, en particulier hydrauliques, du $18^{\text {ème }}$ siècle à nos jours.
\end{abstract}

